\title{
On a Time-Varying Parameter Adaptive Self-Organizing System in the Presence of Large Outliers in Observations
}

\author{
Rimantas PUPEIKIS \\ Institute of Mathematics and Informatics \\ Akademijos 4, LT-08663 Vilnius, Lithuania \\ e-mail:pupeikis@ktl.mii.lt
}

Received: February 2009; accepted: December 2009

\begin{abstract}
In the previous papers (Pupeikis, 2000; Genov et al., 2006; Atanasov and Pupeikis, 2009), a direct approach for estimating the parameters of a discrete-time linear time-invariant (LTI) dynamic system, acting in a closed-loop in the case of additive noise with contaminating outliers uniformly spread in it, is presented. It is assumed there that the parameters of the LQG (Linear Quadratic Gaussian) controller are unknown, as well as known beforehand, too. The aim of the given paper is development of a minimum variance control (MVC) approach for a closedloop discrete-time linear dynamic system when slowly or suddenly time-varying coefficients of the transfer function of such a system as well as that of a minimum variance (MV) controller are not known and ought to be estimated. The recursive parametric identification of an open-loop system and determination of the coefficients of the MV controller are performed in each current operation by processing observations in the case of additive noise at the output with contaminating outliers uniformly spread in it. The robust recursive technique, based on the S-algorithm, with a version of Shweppe's GM-estimator and with discounting previous data, used in the estimation, by introducing a constant as well as time-varying forgetting factors in the abovementioned estimator, is applied here in the calculation of estimates of the parameters of a dynamic system. Then, the recursive parameter estimates are used in each current iteration to determine unknown parameters of the MV controller. Afterwards, the current value of the MV control signal is found in each operation, and it is used to generate the output of the system, too. The results of numerical simulation by computer are presented and discussed.
\end{abstract}

Keywords: adaptive systems, closed-loop, self-tuning controller, the minimum variance control law, parametric identification, observations, outliers.

\section{Introduction}

The minimum variance control (MVC) and generalised MVC (GMVC) algorithms were the first that were designed specially for self-tuning applications and are now considered 'classical' formulations (Äström and Wittenmark, 1987; Thamm, 1999). The algorithms described there can be implemented as self-tuning controllers that underpin the design and development of a modern model based predictive control approach. It is known (Hägglund, 1983), that in order to track time-varying system model parameters the recursive 
parametric identification algorithms sensitive to their changes are required. Usually they rely on the description of variations in the parameters. Therefore an obvious approach to estimate the time-varying parameters is to introduce some model for the variations, i.e., linearly dependent on the time coefficients of a linear time-variant (LTV) dynamic system. However, the possibly most common method, as noted in Waller and Saxén (2000), is to discount the previous data in the parametric estimation by introducing a forgetting factor according to Hägglund (1985), Ljung and Gunnarsson (1990) in the quadratic prediction error criterion to be minimized if the parameters of the LTV system to be controlled have been slowly time varying.

Note that, by the MV control, stochastic characteristics of the additive noise acting on the output of the system to be controlled are usually unknown in advance. Despite that, it is frequently assumed that system's output is affected by Gaussian disturbance. However, nonnormal noise, and particularly the presence of outliers (Huber, 1964; Lucas, 1996), degrades the performance of a system acting in an open- as well as a closedloop. In such a case, ordinary recursive techniques used for parametric identification of any control systems, are inefficient, as a rule. It is known (Novovičova, 1987; Pupeikis, 1991, 2000) that, for parametric identification of open-loop, as well as of closed-loop systems, robust recursive techniques ought to be applied that are efficient in the case of nonnormal noise. Similar techniques could be used for systems with output nonlinearities, too (Vörös, 2010).

To implement the self-tuning MV controller, it is necessary, firstly, to recursively estimate the LTV system's model parameters, slowly varying in time in such a noisy environment and, secondly, to determine the controller coefficients in each current operation (see Evans, 2008; Fig. 1) that are recalculated using the values of abovementioned estimates. Then, the current value of the control signal, based on the values of the reference signal and that of input-noisy output of a system, multiplied by the respective weighting coefficients, is obtained according to Fig. 1.

In Section 2, a statement of the problem is presented. In Section 3, an ordinary direct approach is described for identification of time-varying parameters of the LTV system transfer function. We analyze a recursive parametric identification, based on GM-estimators in the presence of outliers in the LTV system's output observations when the parameters to be calculated have been varying in time, in Section 4. Section 5 presents the simulation and parametric identification results. Section 6 contains conclusions.

\section{Statement of the Problem}

Assume that a system to be observed is causal and LTV with one output $\{y(k)\}$ and one input $\{u(k)\}$, expressed by the equation

$$
y(k)=G_{0}\left(q^{-1} ; \theta(k)\right) u(k)+\underbrace{H_{0}\left(q^{-1} ; \varphi(k)\right) \xi(k)}_{v(k)},
$$

that consists of two parts (Fig. 2): a system model $G_{0}\left(q^{-1} ; \theta(k)\right)$ and a noise model $H_{0}\left(q^{-1} ; \varphi(k)\right)$. Here $k$ is the current number of observations of a respective signal, 


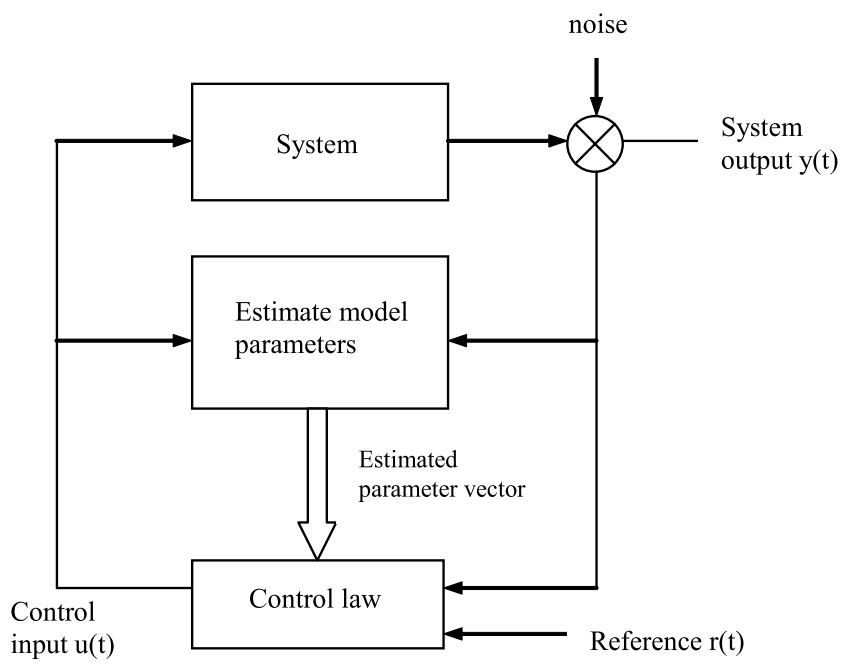

Fig. 1. The parameter adaptive self-organizing system.

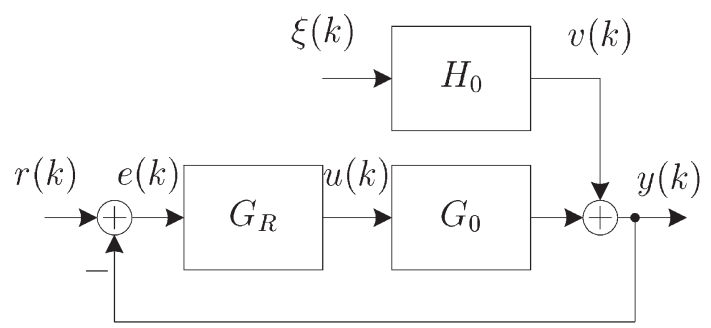

Fig. 2. The closed-loop system to be observed. Here $G_{R} \equiv G_{R}\left(q^{-1} ; \alpha(k)\right) G_{0} \equiv G_{0}\left(q^{-1} ; \theta(k)\right)$, and $H_{0} \equiv H_{0}\left(q^{-1} ; \varphi(k)\right)$.

$\theta(k), \varphi(k)$ are unknown slowly time-varying parameter vectors to be estimated, $q^{-1}$ is the backward time-shift operator such that $q^{-1} u(k)=u(k-1)$, and $H_{0}\left(q^{-1}, \varphi(k)\right)$ is an inversely stable monic filter (Forsell and Ljung, 1999). Given model (1) and the measured data

$$
\mathbf{Z}^{N}=\{u(1), u(2), \ldots, u(N), y(1), y(2), \ldots, y(N)\}
$$

and assuming that the white noise $\{\xi(k)\}, k=1,2, \ldots$ is really a sequence of independent identically distributed variables with an $\epsilon$-contaminated distribution of the form

$$
p(\xi(k))=(1-\epsilon) N\left(0, \sigma_{\mu}^{2}\right)+\epsilon N\left(0, \sigma_{\varsigma}^{2}\right),
$$

and the variance

$$
\sigma_{\xi}^{2}=(1-\epsilon) \sigma_{\mu}^{2}+\epsilon \sigma_{\varsigma}^{2}
$$


let us suppose that $\{\xi(k)\}$ is used to generate unmeasurable noise $\{v(k)\}$. Here $p\{\xi(k)\}$ is the probability density distribution of the sequence $\{\xi(k)\}, k=1,2, \ldots$;

$$
\xi(k)=\left(1-\gamma_{k}\right) \mu_{k}+\gamma_{k} \varsigma_{k}
$$

is the value of the sequence $\{\xi(k)\}, k=1,2, \ldots$ at a time moment $k ; \gamma$ is a random variable, taking values 0 or 1 with probabilities $p\left(\gamma_{k}=0\right)=1-\epsilon, p\left(\gamma_{k}=1\right)=\epsilon ; \mu_{k}, \varsigma_{k}$ are sequences of independent Gaussian variables with zero means and variances $\sigma_{\mu}^{2}, \sigma_{\varsigma}^{2}$, respectively; besides, $\sigma_{\mu}<\sigma_{\varsigma} ; 0 \leqslant \epsilon \leqslant 1$ is the unknown fraction of contamination.

The aim of the given paper is to design a slowly or suddenly time-varying parameter adaptive self-organizing system with the MV control law, shown in Fig. 1, in the case of additive noise $\{v(k)\}$, that contains large outliers and corrupts the output $\{y(k)\}$ of the LTI system (see Fig. 2).

\section{The Direct Approach for a System with Time-Varying Parameters}

The direct approach ignores the feedback and identifies the system $G_{0}\left(q^{-1} ; \theta\right)$ that uses the measurements of the input $u(k)$ and output $y(k) \forall k=1,2, \ldots$ [2], assuming that the white noise $\{\xi(k)\}, k=1,2, \ldots$ is stationary with the following characteristics:

$$
E\{\xi(k)\}=0, \quad E\{\xi(k) \xi(k+\tau)\}=\sigma_{\xi}^{2} \delta(\tau)
$$

where $E\{\xi(k)\}$ is the mean value, $\sigma_{\xi}^{2}$ is the variance, $\delta(\tau)$ is the Kronecker delta function. Using the direct parameric identification method, one has to estimate the prediction error value $\theta(\hat{k})_{N}$ of the vector of parameters $\theta(k)$ by means of

$$
\hat{\theta}_{N}(k)=\arg \min _{\theta \in D_{M}} V_{N}\left(\theta(k), Z^{N}\right) .
$$

Here

$$
V_{N}\left(\theta(k), Z^{N}\right)=\frac{1}{N} \sum_{k=1}^{N} w(k) e_{F}^{T}(k, \theta(k)) \Lambda^{-1} e_{F}^{T}(k, \theta(k))
$$

with

$$
e_{F}(k, \theta(k))=L(q, \theta(k)) \epsilon(k, \theta(k))
$$

$w(k)=\lambda^{N-k}(k)$ is a set of the weighting coefficients varying in time,

$$
\lambda(k)=\lambda_{0} \lambda(k-1)+\left(1-\lambda_{0}\right)
$$

with $\lambda_{0}<1$ and $\lambda(0)<1,0<\lambda(k) \leqslant 1$ is a forgetting factor used to discount previously processed observations (Isermann, 1988), $\boldsymbol{\Lambda}$ is a symmetric, positive definite 
weighting matrix, and $L\left(q^{-1} ; \theta(k)\right)$ is a monic prefilter that can be used to enhance certain frequency regions (Forsell and Ljung, 1999). The prediction error is calculated by the formula

$$
\begin{aligned}
\epsilon(k, \theta(k)) & =y(k)-\hat{y}(k, \hat{\theta}(k)) \\
& =H^{-1}\left(q^{-1} ; \hat{\varphi}(k)\right)\left[y(k)-G\left(q^{-1} ; \hat{\theta}(k)\right) u(k)\right] .
\end{aligned}
$$

Here the output $y(k)$ of the general model of the LTV system $G\left(q^{-1} ; \theta(k)\right)$ and noise filter $H\left(q^{-1} ; \varphi(k)\right)$, respectively, is of the form

$$
y(k)=G\left(q^{-1} ; \theta(k)\right) u(k)+H\left(q^{-1} ; \varphi(k)\right) \xi(k),
$$

where $G\left(q^{-1} ; \theta(k)\right)$ corresponds to the first part of (1) and $H\left(q^{-1} ; \varphi(k)\right)$ to the second one. Then, the one-step-ahead predictor for the model structure (12) is

$$
\begin{aligned}
\hat{y}(k, \hat{\theta}(k))= & H^{-1}\left(q^{-1} ; \hat{\varphi}(k)\right) G\left(q^{-1} ; \hat{\theta}(k)\right) u(k) \\
& +\left[1-H^{-1}\left(q^{-1} ; \hat{\varphi}(k)\right)\right] y(k) .
\end{aligned}
$$

Here $\hat{\varphi}(k)$ is the estimate of the parameter vector $\varphi(k)$. The parameter vector $\theta(k)$ can be determined by an ordinary prediction error method, based on the recursive LS (RLS):

$$
\begin{aligned}
& \hat{\theta}(k)=\hat{\theta}(k-1)+\frac{\boldsymbol{\Gamma}(k-1) \mathbf{z}(k)}{\lambda(k)+\mathbf{z}^{T}(k) \boldsymbol{\Gamma}(k-1) \mathbf{z}(k)} \hat{\varepsilon}(k), \\
& \boldsymbol{\Gamma}(k)=\lambda(k)^{-1}\left\{\boldsymbol{\Gamma}(k-1)-\frac{\boldsymbol{\Gamma}(k-1) \mathbf{z}(k) \mathbf{z}^{T}(k) \boldsymbol{\Gamma}(k-1)}{\lambda(k)+\mathbf{z}^{T}(k) \boldsymbol{\Gamma}(k-1) \mathbf{z}(k)}\right\},
\end{aligned}
$$

with the vector of observations $\mathbf{z}^{T}(k)=[-y(k-1), \ldots,-y(k-m), u(k-1), \ldots, u(k-m)]$, and some initial values of the vector $\hat{\theta}(0)$ and matrix $\boldsymbol{\Gamma}(0)$, introducing the forgetting factor $0<\lambda(k) \leqslant 1$ in the RLS. Here

$$
\hat{\theta}^{T}(k)=\left[\hat{\mathbf{a}}^{T}(k), \hat{\mathbf{b}}^{T}(k)\right]=\left[\hat{a}_{1}(k), \ldots, \hat{a}_{m}(k), \hat{b}_{0}(k), \hat{b}_{1}(k), \ldots, \hat{b}_{m}(k)\right],
$$

is the current estimate of the vector

$$
\theta^{T}(k)=\left(\mathbf{a}^{T}(k), \mathbf{b}^{T}(k)\right)=\left(a_{1}(k), \ldots, a_{m}(k), b_{0}(k), b_{1}(k), \ldots, b_{m}(k)\right),
$$

and

$$
\hat{\varepsilon}(k)=y(k)-\mathbf{z}^{T}(k) \hat{\theta}(k-1)
$$

is the prediction error of the current $k$-th iteration, respectively, where $G_{0}\left(q^{-1} ; \theta\right)$ is the system transfer function of the form 


$$
\begin{aligned}
G_{0}\left(q^{-1} ; \theta(k)\right) & =\frac{B\left(q^{-1} ; \mathbf{b}(k)\right)}{A\left(q^{-1} ; \mathbf{a}(k)\right)} \\
& =\frac{b_{0}(k)+b_{1}(k) q^{-1}+b_{2}(k) q^{-2}+\ldots+b_{m}(k) q^{-m}}{1+a_{1}(k) q^{-1}+\ldots+a_{m}(k) q^{-m}} .
\end{aligned}
$$

Here $\mathbf{b}^{T}(k)=\left(b_{0}(k), b_{1}(k), \ldots, b_{m}(k)\right)$, and $\mathbf{a}^{T}=\left(a_{1}(k), \ldots, a_{m}(k)\right)$ are vectors of the parameters to be estimated.

It is known that RLS with $\lambda(k)=1$, used to calculate time-constant parameters of the linear time-invariant system, is efficient only in the case where

$$
H_{0}\left(q^{-1} ; \varphi\right)=\frac{1}{1+A\left(q^{-1} ; \mathbf{a}\right)}=\frac{1}{1+a_{1} q^{-1}+\ldots+a_{m} q^{-m}}, \quad \varphi \equiv \mathbf{a}
$$

It could be emphasized that, before the direct parametric identification of the closed-loop, the respective identifiability conditions should be satisfied according to Isermann (1977).

\section{Calculation of Estimates of Time-Varying Parameters in the Presence of Large Outliers}

In the presence of outliers in additive noise one can determine the prediction error estimate $\hat{\theta}_{N}$ of the parameter vector (16) by minimizing

$$
\hat{\theta}_{N}(k)=\arg \min _{\theta(k) \in D_{M}} \hat{V}_{N}\left(\theta(k), \mathbf{Z}^{N}\right)
$$

with

$$
\hat{V}_{N}\left(\theta(k), \mathbf{Z}^{N}\right)=\frac{1}{N} \sum_{k=1}^{N} w(k) \rho\left(e_{F}(k, \theta(k) / s)\right) .
$$

Here $\hat{\theta}_{N}(k)$ is the robust estimate of the parameter vector $\theta(k)$, established by processing $N$ pairs of input-output samples; $s$ is the scale of residuals (examples of the scale are the standard deviation, the median, absolute deviation from the median, etc.,); $\rho(\cdot)$ is a real-valued function that is even and nondecreasing for positive residuals, and $\rho(0)=0$, $\psi=\rho^{\prime}$.

For the Huber $M$-estimator, the $\rho$-function is given by Huber (1984)

$$
\rho(x)= \begin{cases}x^{2} / 2 & \text { if }|x| \leqslant c_{H}, \\ c_{H}|x|-c_{H}^{2} / 2 & \text { if }|x|>c_{H},\end{cases}
$$

where $c_{H}$ is a cutoff value. The most often used function $\psi$ is:

$$
\psi(x)= \begin{cases}x & \text { if }|x| \leqslant c_{H} \\ c_{H} \operatorname{sign}(x) & \text { if }|x|>c_{H}\end{cases}
$$


with given $c_{H}>0$. To get a better performance of $\hat{\theta}_{\mathbf{N}}$ in the case of very long-tailed distributions, function (21) satisfying $\psi(x)=0$, if $|x|>c_{H}$, could be selected for some $c_{H}>0$. It is known (Novovičova, 1987) that, in both such cases, i.e., $\epsilon \neq 0$ and $H_{0}\left(q^{-1} ; \varphi\right)$ of form (19), the current $M$-estimates of an unknown vector of parameters $\theta$ of system (1) with $G\left(q^{-1}, \theta\right)$ of form (18), but only in the case of time-constant parameters, can be calculated using three techniques: the $S$-algorithm, the $H$-algorithm, and the $W$-one. All the three of them could be written in the general form:

$$
\begin{aligned}
& \hat{\theta}(k)=\hat{\theta}(k-1)+\frac{\boldsymbol{\Gamma}(k-1) \mathbf{z}(k)}{\gamma(k)+\mathbf{z}^{T}(k) \boldsymbol{\Gamma}(k-1) \mathbf{z}(k)} \beta(k), \\
& \boldsymbol{\Gamma}(k)=\lambda(k)^{-1}\left\{\boldsymbol{\Gamma}(k-1)-\frac{\boldsymbol{\Gamma}(k-1) \mathbf{z}(k) \mathbf{z}^{T}(k) \boldsymbol{\Gamma}(k-1)}{\gamma(k)+\mathbf{z}^{T}(k) \boldsymbol{\Gamma}(k-1) \mathbf{z}(k)}\right\},
\end{aligned}
$$

when they are used to calculate time-varying parameters of the LTV system. Here

$$
\beta(k)=\hat{s} \psi[\alpha(k)]
$$

with

$$
\alpha(k)=\hat{\varepsilon}(k) / \hat{s}
$$

for the $S$ - and $H$-algorithms, and

$$
\beta(k)=\hat{s} \hat{\varepsilon}(k)
$$

for the $W$-algorithm, and

$$
\hat{\varepsilon}(k) / \hat{s}=\left\{y(k)-\mathbf{z}^{T}(k) \hat{\theta}(k-1)\right\} / \hat{s}
$$

is the same for all the three algorithms, while

$$
\gamma(k)=\lambda(k)
$$

for the $H$-algorithm,

$$
\gamma(k)= \begin{cases}\lambda(k) \hat{s} \psi[\alpha(k)] / \hat{\varepsilon}(k)\}^{-1} & \text { as } \hat{\varepsilon}(k) \neq 0 \\ \lambda(k) & \text { as } \hat{\varepsilon}(k)=0\end{cases}
$$

for the $W$-algorithm, and

$$
\gamma(k)=\lambda(k) \psi^{\prime}[\alpha(k)]^{-1}
$$

for the $S$-algorithm. Here $\hat{s}$ is the robust estimate of the scale $s$ of residuals.

Genov et al. (2006) have proposed to use

$$
\beta(k)=\hat{s} \phi_{z 1} \psi\left[\alpha(k) / \phi_{z 2}\right]
$$


and

$$
\lambda(k)= \begin{cases}\phi_{z 1} \psi\left[\alpha(k) / \phi_{z 2}\right] /\left[\alpha(k) / \phi_{z 2}\right] & \text { for } \alpha(k) \neq 0 \\ \phi_{z 1} & \text { for } \alpha(k)=0\end{cases}
$$

respectively, instead of (25) and (30). Here

$$
\phi_{z 1}=\phi_{z 2}=1
$$

for Huber's $M$-estimator;

$$
\phi_{z 1}=\phi_{z}[h(k)], \quad \phi_{z 2}=1
$$

for Mallow’s, and

$$
\phi_{z 1}=\phi_{z 2}=\phi_{z}[h(k)]
$$

for Shweppe's $G M$-estimators [6], respectively, where

$$
\phi_{z}[h(k)]=\sqrt{1-h(k)}
$$

with

$$
h(k)=\mathbf{z}^{T}(k) \boldsymbol{\Gamma}(k) \mathbf{z}(k) .
$$

\section{Simulation Example}

A closed-loop system to be simulated is shown in Fig. 3 and described by a linear difference equation of the form

$$
\begin{aligned}
& \left(1+a_{1}(k) q^{-1}+a_{2}(k) q^{-2}\right) y(k) \\
& \quad=q^{-1}\left(b_{0}(k)+b_{1}(k) q^{-1}\right) u(k)+\left(1+a_{1}(k) q^{-1}+a_{2}(k) q^{-2}\right)^{-1} \xi(k)
\end{aligned}
$$

while the MV controller design equation is (Evans, 2008; Thamm, 1999)

$$
u(k)=\frac{a_{1}(k) y(k)+a_{2}(k) y(k-1)-b_{1}(k) u(k-1)+r(k)}{b_{0}(k)} .
$$

Here $a_{1}(k), a_{2}(k), b_{0}(k)$ and the value of the coefficient $b_{1}(k)$ are time-varying. In the first experiment they varry linearly from $-1.5,0.7,1$ and 0.5 to $-1.4,0.8,1.1$, and 0.6 over 400 observations, respectively (see Fig. 4c), while in the second one coefficients $-1.5,0.7$, and 0.5 suddenly give a jump at $k=100$ observations and obtain the new values $-1.2,0.5,0.25$, correspondingly (Figs. 7, 9). At the same time 


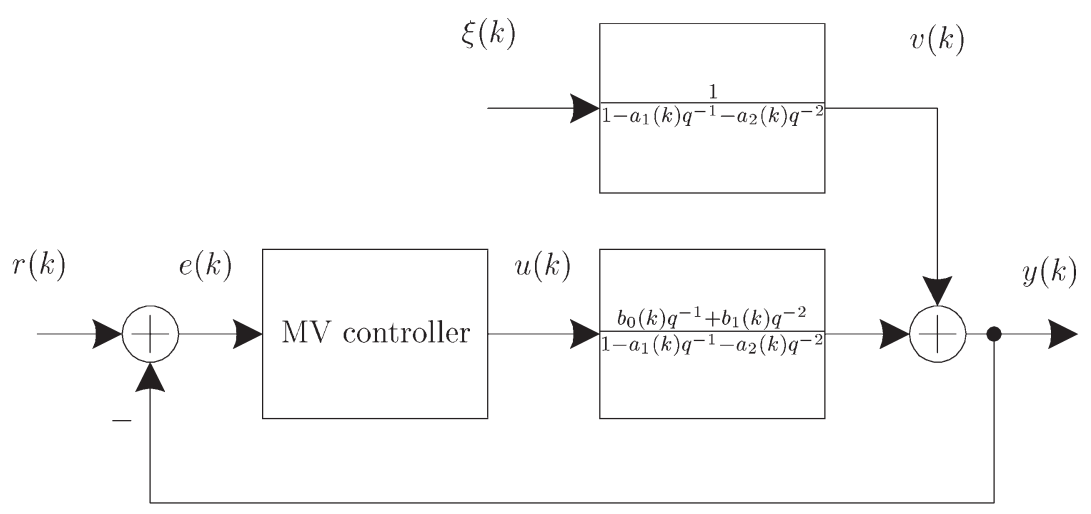

Fig. 3. The closed-loop system with time-varying parameters to be simulated. The current values of respective signals: $r(k)$ is a reference signal, $u(k)$ is a control signal, $y(k)$ is a noisy output, $v(k)$ is an additive correlated noise, $\xi(k)$ is a sequence of independent identically distributed variables with an $\epsilon$-contaminated distribution of form (17), and $e(k)=r(k)-y(k)$ is an error.
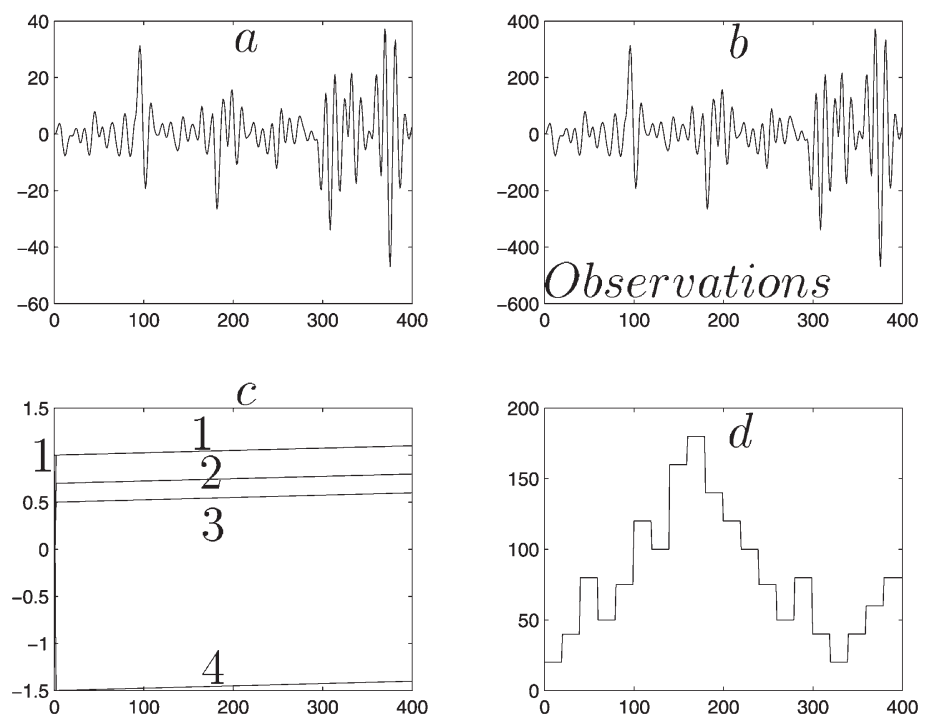

Fig. 4. Two different realizations of the noise $\{v(k)\}$ with outliers (a, b), true parameters linearly in dependence on time $(\mathrm{c}): b_{0}(k)-1, b_{1}(k)-3, a_{1}(k)-4$, and $a_{2}(k)-2$, respectively, and the reference signal (d) for a simulated closed-loop LTV system (see Fig. 3). The fraction of contamination $\epsilon=0.1$.

the parameter $b_{0}(k)$ is still varies linearly over all the set of observations. The output $\{y(k)\}, k=0,1,2, \ldots, 400$ of the closed-loop system will be observed under the additive noise $\{v(k)\}, k=0,1,2, \ldots, 400$ in the presence of large outliers (see Figs. 4a, 4b) with the fraction of contamination $\epsilon=0.1$. Note that both two noise realizations given here are the same except that their amplitudes are artificially increased from one realization to the other by ten times. The reference signal $\{r(k)\}, k=0,1,2, \ldots, 400$ is given in Fig. 4d. 
The parameter adaptive self-organizing system has been implemented here according to the structure shown in Fig. 1. Firstly, the initial values of estimates $\hat{a}_{1}(k), \hat{a}_{2}(k), \hat{b}_{0}(k), \hat{b}_{1}(k)$ of the true parameters $a_{1}(k), a_{2}(k), b_{0}(k), b_{1}(k)$ of (39) were calculated by the ordinary LS with Mallow's estimator using 23 pairs of observations of $u(k), y(k)$. Secondly, we recursively calculate the estimates $\hat{a}_{1}(k), \hat{a}_{2}(k), \hat{b}_{0}(k), \hat{b}_{1}(k)$ of the same time-varying parameters $a_{1}(k), a_{2}(k), b_{0}(k), b_{1}(k)$ by processing $k=$ $24,25, \ldots, 400$ observations of the control signal $\{u(k)\}$ and the output $\{y(k)\}$ in each current iteration, using S-algorithm (24) with a version of Shweppe's GMestimator (36)-(38) (see Figs. 5c, 5d, 6c, 6d, 7, 8c, 8d, 9, 10c, 10d), and constant or time-varying forgetting factors $\lambda$. Note that constant as well as time-varying values of $\lambda$ have been applied for estimation of suddenly jumping coefficients $-1.5,0.7$, and 0.5 . For estimation linearly varying coefficients only constant values of forgetting factor have been used. The output signals, noisy with oytliers $\{y(k)\}$ and the true signal $y_{*}(k)$, of the same LTV system (39) to be processed have been generated as follows:
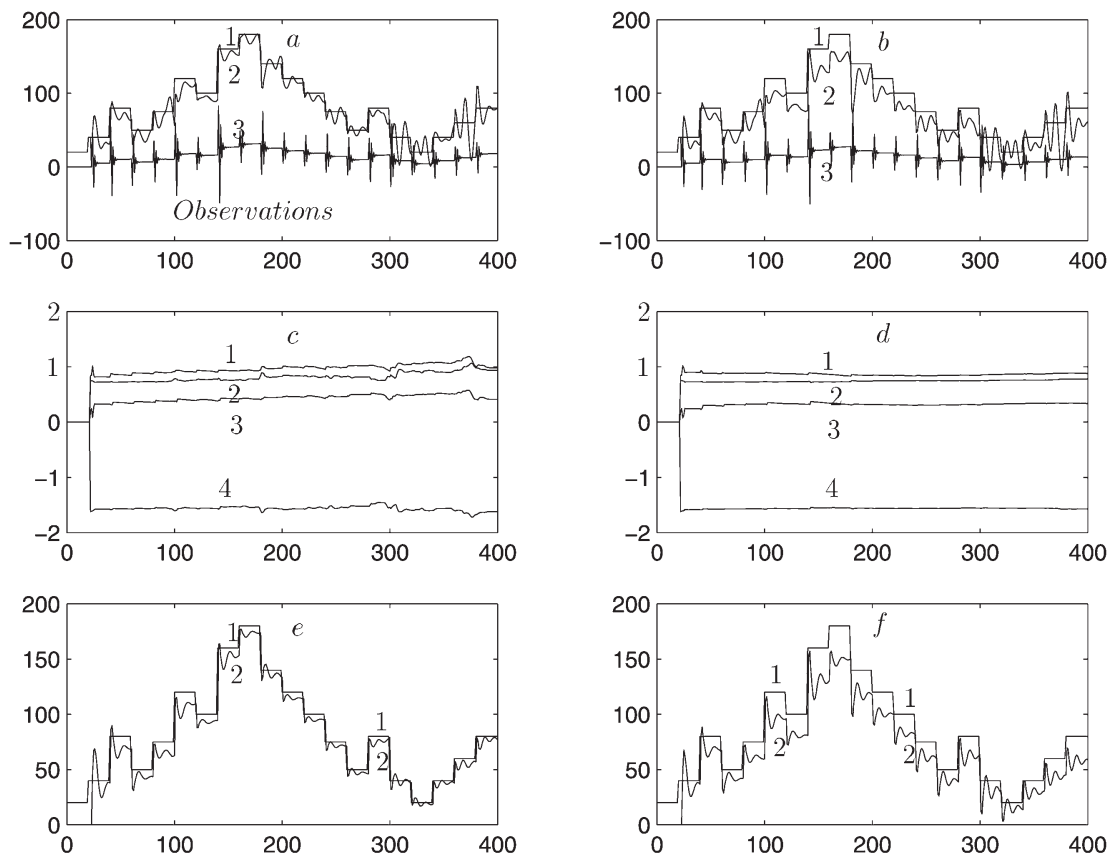

Fig. 5. The signals and parametric identification results, in the presence of additive noise, given in Fig. 4a, depending on the number of recursive iterations: $x$-axis is the number of iterations, $y$-axis is meanings of the signals $(a, b, e, f)$ and current estimates of linearly time varying parameters $(c, d) ; a, b, e, f$ are signals: the reference signal $\{r(k)\}-1$, output signals: noisy $\{y(k)\}-2(a, b)$, true $\left\{y_{*}(k)\right\}-2(e, f)$, the control signal $\{u(k)\}-3$, respectively; $c, d$ denote current estimates of linearly varying parameters $b_{0}(k), b_{1}(k), a_{1}(k), a_{2}(k)$ (see Fig. 4c): $\hat{b}_{0}(k), \hat{b}_{1}(k), \hat{a}_{1}(k), \hat{a}_{2}(k)-1,3,4,2$, respectively. In S-algorithm (24), the forgetting factor is: $\lambda=1(b, d, f)$ and $\lambda=0.955(a, c, e)$. 

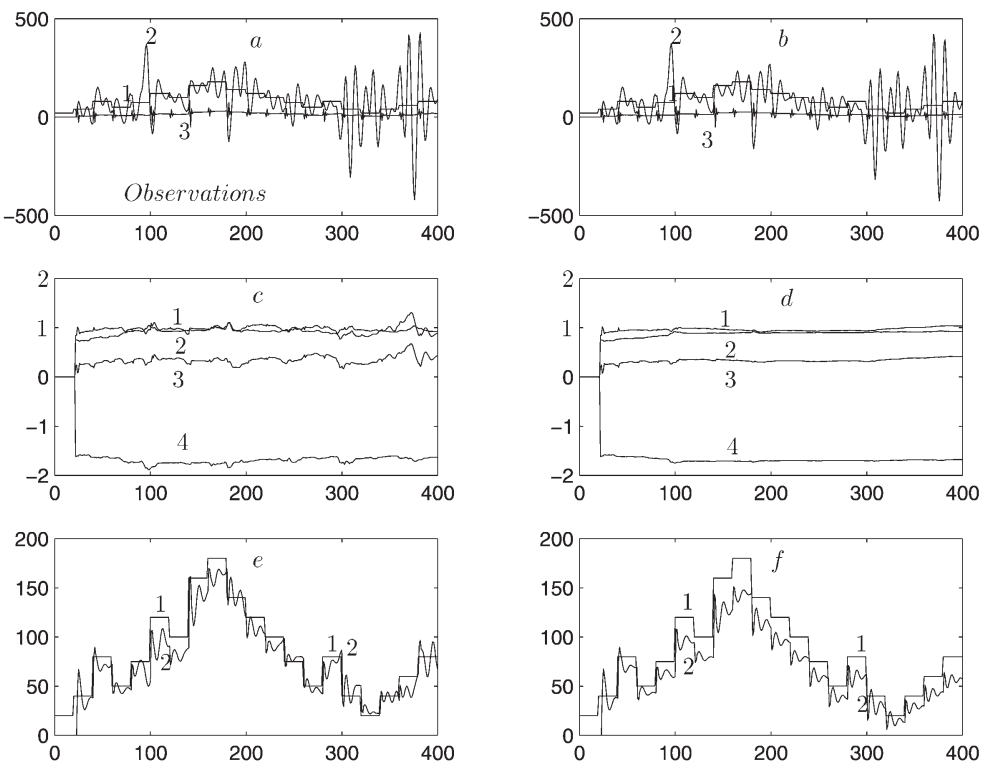

Fig. 6. The signals and parametric identification results in the presence of additive noise (see Fig. 4b). Other values and notation are the same as in Fig. 5.
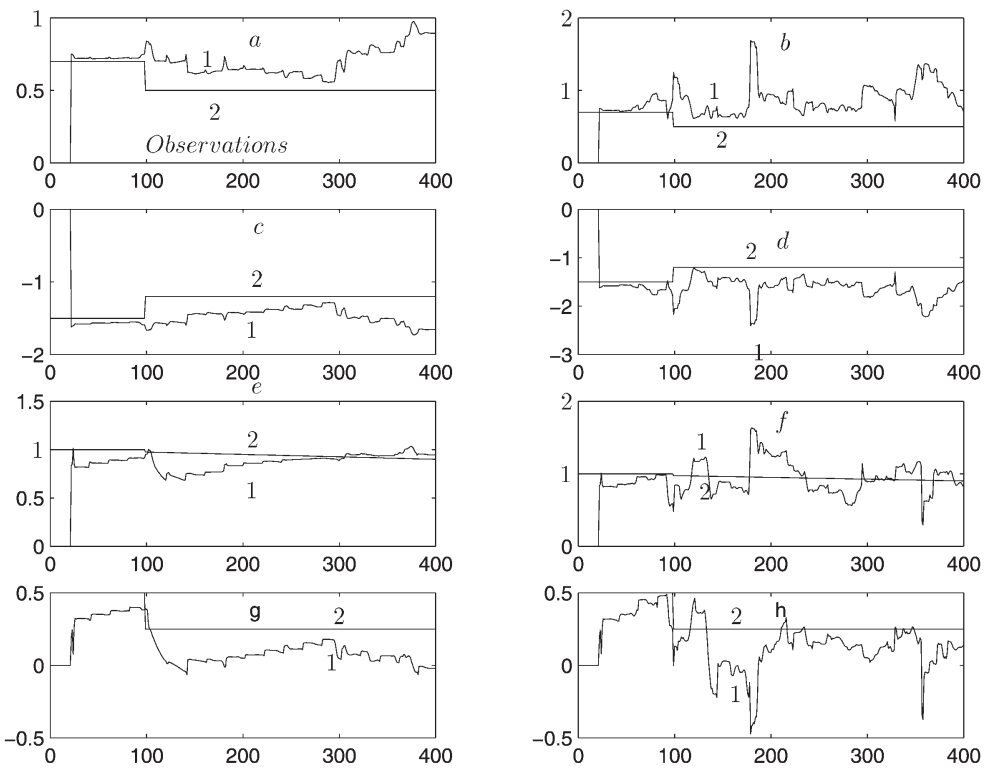

Fig. 7. Current estimates $\hat{a}_{2}(k)(a, b), \hat{a}_{1}(k)(c, d), \hat{b}_{0}(k)(e, f), \hat{b}_{1}(k)(g, h)$ of the parameters $a_{2}(k), a_{1}(k)$, $b_{0}(k), b_{1}(k)$, respectively, dependent on the number of recursive iterations in the presence of additive noise (see Fig. 4a). The parameters $a_{1}(k), a_{2}(k)$ and $b_{1}(k)$ give a jump at $k=100$ observations while the parameter $b_{0}(k)$ varies linearly over the same set of observations. The estimates $\hat{b}_{0}(k), \hat{b}_{1}(k), \hat{a}_{1}(k), \hat{a}_{2}(k)$ correspond to curves 1 , while the true parameters $b_{0}(k), b_{1}(k), a_{1}(k), a_{2}(k)$ with a jump and without it correspond to curves 2 . The forgetting factor $\lambda$ is constant and equal to $0.955(a, c, e, g)$ and varying in time according to (10), where $\lambda_{0}=0.972(b, d, f, h)$. 

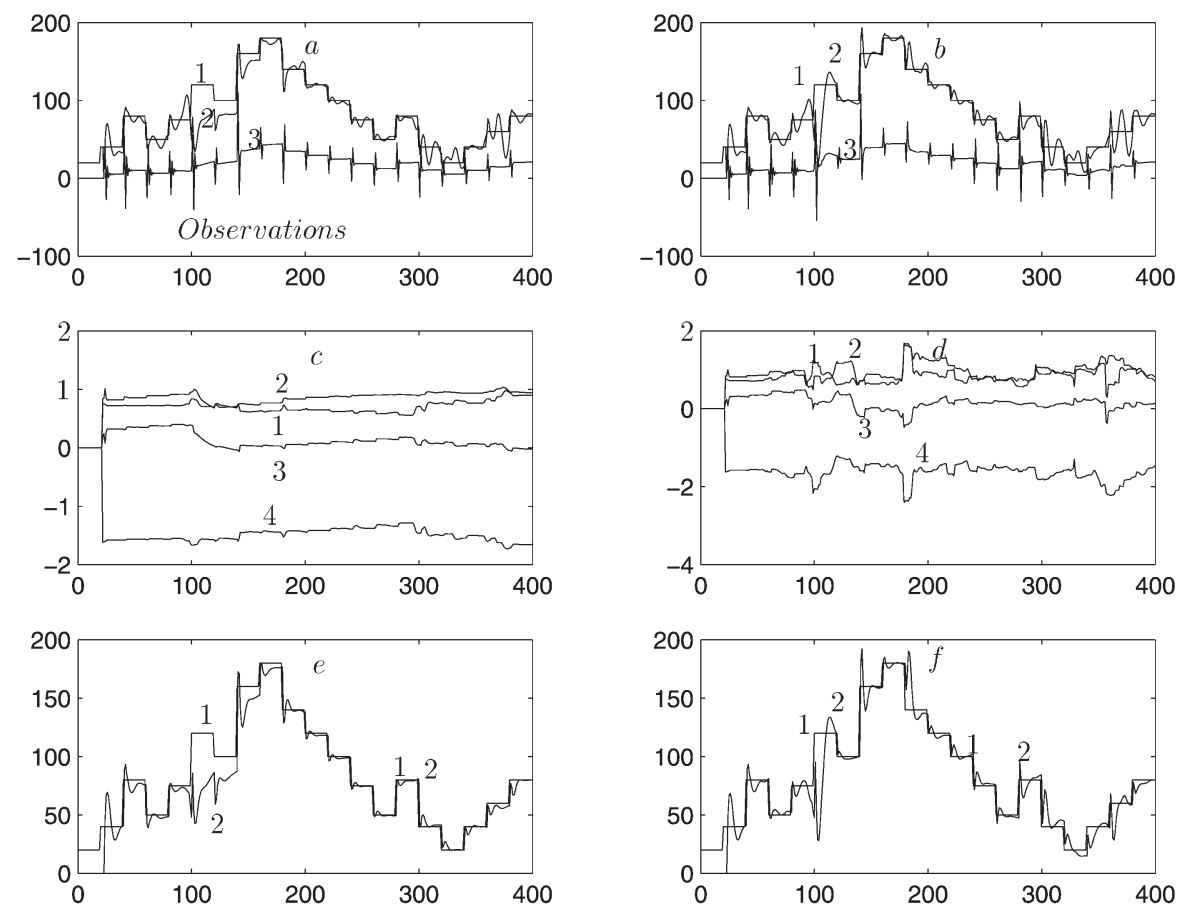

Fig. 8. The signals and parametric identification results, in the presence of additive noise (see Fig. 4a), dependent on the number of recursive iterations: $x$-axis is the number of iterations, $y$-axis is meanings of the signals $(a, b, e, f)$ and current estimates $(c, d) ; a, b, e, f$ are signals: the reference signal $\{r(k)\}-1$, output signals: noisy $\{y(k)\}-2(a, b)$, true $\left\{y_{*}(k)\right\}-2(e, f)$, the control signal $\{u(k)\}-3$, respectively; $c, d$ denote current estimates of parameters $b_{0}(k), b_{1}(k), a_{1}(k), a_{2}(k)$ (see Fig. 7): $\hat{b}_{0}, \hat{b}_{1}, \hat{a}_{1}, \hat{a}_{2}-1,3,4,2$, respectively. In $\mathrm{S}$-algorithm (24) the forgetting factor $\lambda$ is constant and equal to $0.955(a, c, e)$ and time-varying according to (10), where $\lambda_{0}=0.972(b, d, f)$.

$$
\begin{aligned}
& y(k)=y_{*}(k)+\left(1+a_{1}(k) q^{-1}+a_{2}(k) q^{-2}\right)^{-1} \xi(k), \\
& y_{*}(k)=q^{-1}\left(b_{0}(k)+b_{1}(k) q^{-1}\right) u(k)-\left(a_{1}(k) q^{-1}+a_{2}(k) q^{-2}\right) y_{*}(k),
\end{aligned}
$$

with

$$
u(k)=\frac{\hat{a}_{1}(k) \hat{y}(k)+\hat{a}_{2}(k) \hat{y}(k-1)-\hat{b}_{1}(k) u(k-1)+r(k)}{\hat{b}_{0}(k)},
$$

and

$$
\hat{y}(k)=q^{-1}\left(\hat{b}_{0}(k)+\hat{b}_{1}(k) q^{-1}\right) u(k)-\left(\hat{a}_{1}(k) q^{-1}+\hat{a}_{2}(k) q^{-2}\right) \hat{y}(k),
$$

respectively, where the values of the noiseless auxiliary signal $\{\hat{y}(k)\}$ for determination of the current value of control signal $u(k)$ are applied, and the current estimates 

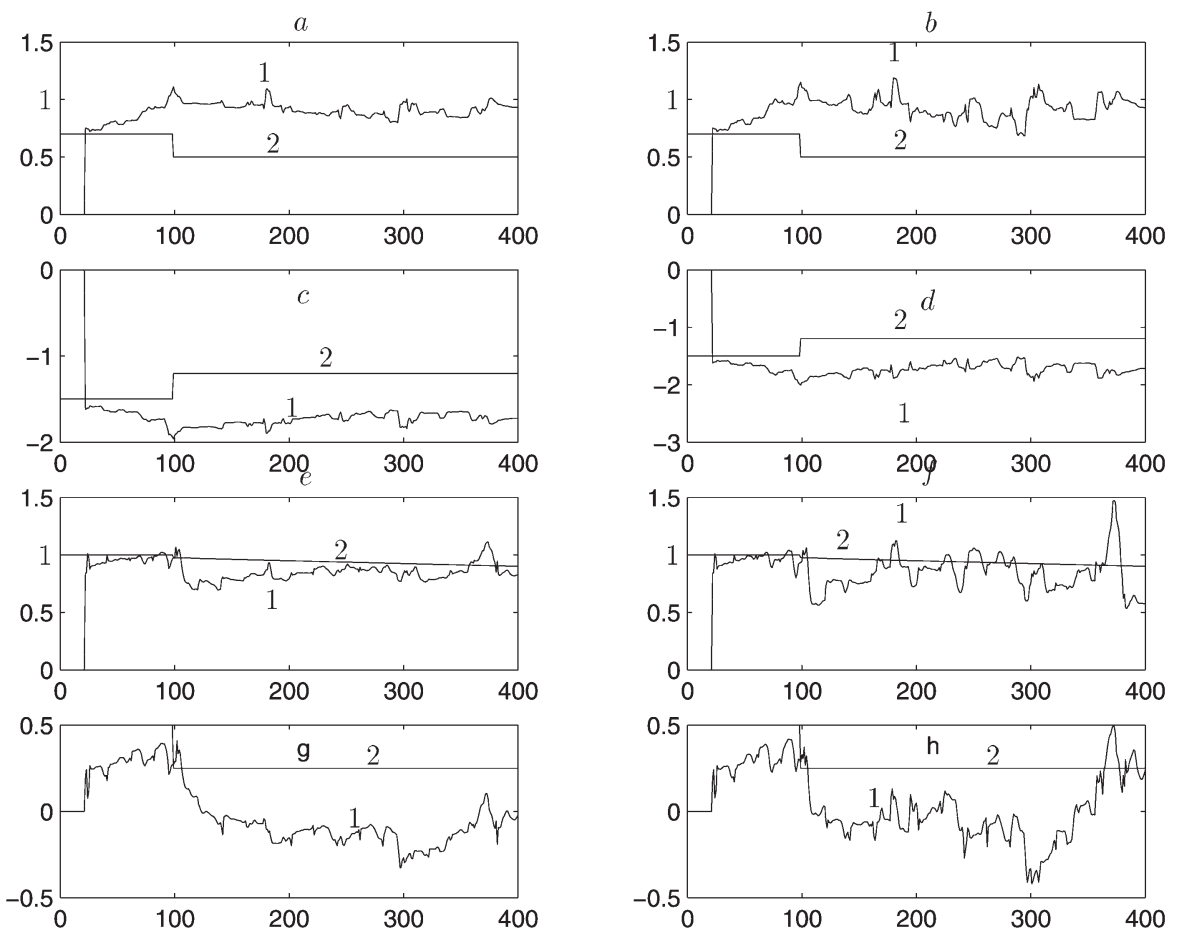

Fig. 9. Current estimates $\hat{a}_{2}(k)(\mathrm{a}, \mathrm{b}), \hat{a}_{1}(k)(\mathrm{c}, \mathrm{d}), \hat{b}_{0}(k)(\mathrm{e}, \mathrm{f}), \hat{b}_{1}(k)(\mathrm{g}, \mathrm{h})$ of the parameters $a_{2}(k), a_{1}(k)$, $b_{0}(k), b_{1}(k)$, respectively, dependent on the number of recursive iterations in the presence of additive noise (see Fig. 4b). Other values and notation are the same as in Fig. 7.

$\hat{a}_{1}(k), \hat{a}_{2}(k), \hat{b}_{0}(k), \hat{b}_{1}(k)$, obtained by recursive S-algorithm (24), are used. Note that the current value of control signal could be generated as follows:

$$
u(k)=\frac{\hat{a}_{1}(k) y(k)+\hat{a}_{2}(k) y(k-1)-\hat{b}_{1}(k) u(k-1)+r(k)}{\hat{b}_{0}(k)} .
$$

However in such a case, the transfer of meanings of large outliers proceeds in random noise appearing in output observations $\{y(k)\} k=24,25, \ldots, 400$. Therefore, we propose here in each current operation to generate an auxiliary output signal $y(k)$ according to (44) that will be without outliers (Pupeikis, 2009).

It follows that the accuracy of estimates $\hat{a}_{1}(k), \hat{a}_{2}(k), \hat{b}_{0}(k), \hat{b}_{1}(k)$ of the parameters $a_{1}(k), a_{2}(k), b_{0}(k), b_{1}(k)$, obtained by recursive procedure (24) (see Figs. 5c, 5d, 6c, 6d, $7,8 \mathrm{c}, 8 \mathrm{~d}, 9,10 \mathrm{c}, 10 \mathrm{~d}$ ), decreases when the amplitudes of values of the additive noise $\{v(k)\}$ with outliers in it are increasing (see Fig. 4a, 4b). In the case of slowly linearly varying parameters of difference equation (39) the true output signal $\left\{y_{*}(k)\right\}$ (42) tracks the reference signal $\{r(k)\}$ enough accurately even for large outliers (Fig. 4b) if the forgetting factor $\lambda=0.955$ is chosen (see Fig. 6e). Comparing the results obtained for different but constant forgetting factors (see Figs. 5e, 5f, and 6e, 6f, respectively), one 

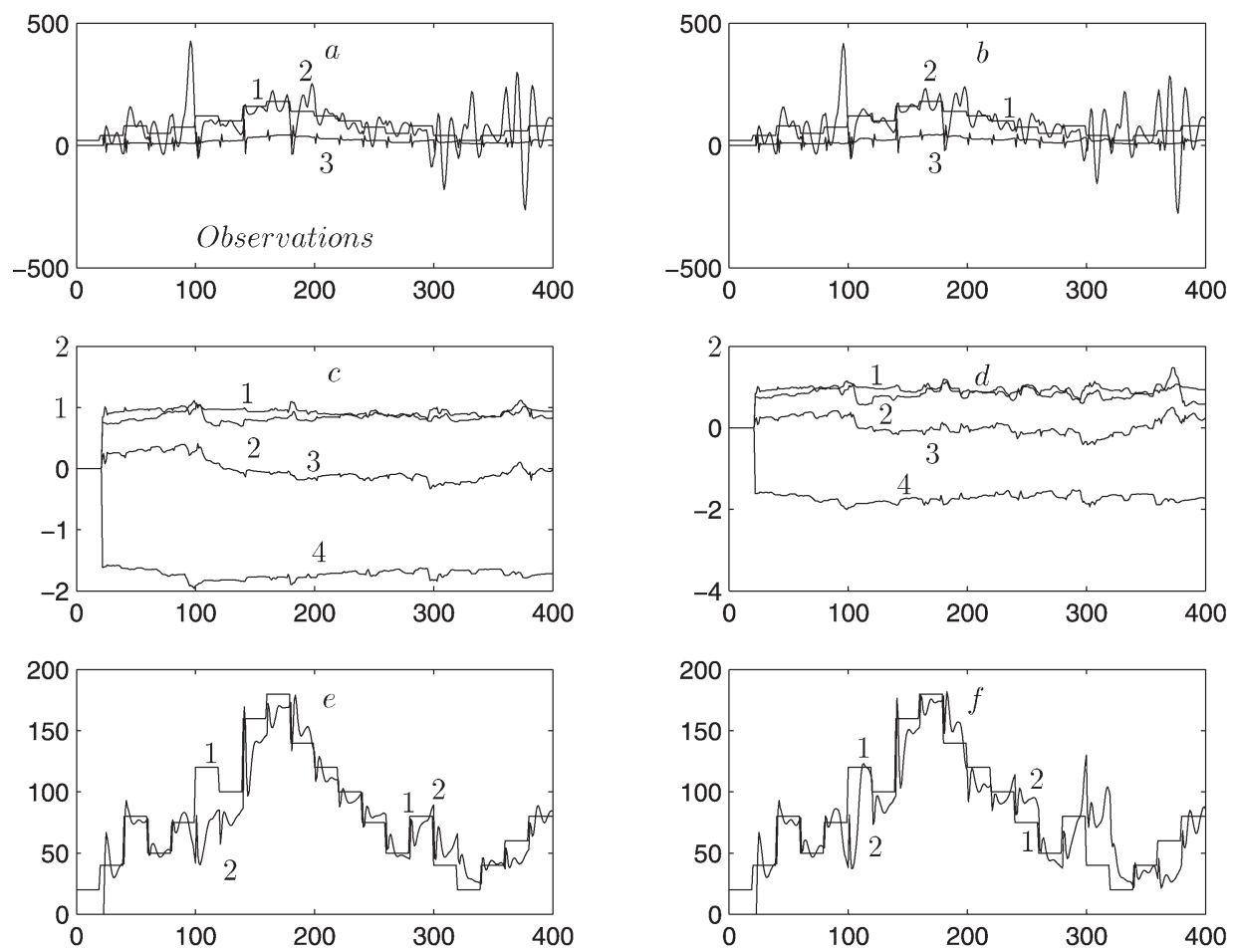

Fig. 10. The signals and parametric identification results in the presence of additive noise (see Fig. 4b) dependent on the number of recursive iterations. In $c, d$, current estimates of the parameters $b_{0}(k), b_{1}(k), a_{1}(k), a_{2}(k)$ (see Fig. 9): $\hat{b}_{0}, \hat{b}_{1}, \hat{a}_{1}, \hat{a}_{2}-1,3,4,2$, respectively. Other values and notation are the same as in Fig. 8.

can state, that in the case of slowly linearly varying parameters the true output signal $\left\{y_{*}(k)\right\}$ tracks the reference signal $\{r(k)\}$ better if $\lambda<1$. On the other hand, comparing the results obtained for constant and time-varying forgetting factors, one can notice, that the true output signal $\left\{y_{*}(k)\right\}$ tracks the reference signal $\{r(k)\}$ even better in the case of suddenly jumping parameters of the same equation if $\lambda$ is constant (see Figs. 8e, 8f, $10 \mathrm{e}, 10 \mathrm{f})$. However, the tracking accuracy of respective parameters by their estimates is insufficient in spite that constant or varying in time $\lambda$ is applied (see Figs. 7, 8c, 8d, 9, 10c, 10d). Therefore it is important to use the methods more sensitive to sudden changes in values of the parameters when calculating the current values of estimates of the respective parameters of difference equation (39) (Isermann, 1988; Ljung and Gunnarsson, 1990).

\section{Conclusions}

Despite that the MV approach has been worked out for a random disturbance generated from the statistically independent and stationary sequence with (6), it appears to be also applicable in the presence of large, but rare outliers in output observations, in case the 
robust recursive parametric identification algorithms are used. The recursive estimates, obtained by S-algorithm (24) with the version of Shweppe's GM-estimator (36)-(38) with the constant, but less than a unit, forgetting factor, track the respective true slowly linearly varying values of parameters more rapidly than that calculated by the same ordinary procedure without discounting older observations in the estimation process. At the same time the true output $\left\{y_{*}(k)\right\}$ of the same system tracks the reference signal $\{r(k)\}$ accurately enough. On the other hand, in the case of suddenly jumping parameters of the LTV system, more sensitive methods are required because the recursive S-algorithm (24) is unable to generate estimates of the parameters with a high tracking abilities, even if the time-varying forgetting factor is used in recursive formulas.

\section{References}

Atanasov, N., Pupeikis, R. (2009). On recursive calculation of M- and GM-estimates by direct identification in LQR control system. Informatica, 20(1), 3-22.

Ȧström, K.J., Wittenmark, B. (1987). Computer Controlled Systems. Mir, Moscow (in Russian).

Evans, G. (2008). Self Tuning and Adaptive Control Coursework.

http: / / www . taumuon.co.uk/cv/SelfTuningAdaptiveControl.doc.

Forsell, U., Ljung, L. (1999). Closed-loop identification revisited. Automatica, 35, 1215-1241.

Genov, D.G., Atanasov, N.R., Pupeikis, R. (2006). Robust M- and GM-estimators for closed-loop identification using the direct approach. In: Proc. of Int. Conf. on Automat. and Informat. Sofia, pp. 193-196.

Hägglund, T. (1983). New estimation techniques for adaptive control. Doctoral Dissertation. Department of Automatic Control, Lund University, Sweden.

Hägglund, T. (1985). Recursive estimation of slowly time-varying parameters. In: 7th IFAC Symp. Identification Syst. Param. Estim. York Proc. Oxford, Pergamon.

Huber, P.J. (1964). Robust estimation of a location parameter. Ann. Math. Statist., 35, 73-101.

Huber, P.J. (1984). Robust Statistics. Mir, Moscow (in Russian).

Isermann, R. (1977). Digitale Regelsysteme. Springer-Verlag, Berlin.

Isermann, R. (1988). Identifikation Dynamischer Systeme. Band II. Springer-Verlag, Berlin.

Ljung, L., Gunnarsson, S. (1990). Adaptation and tracking in system identification - a survey. Automatica, 1, $7-21$.

Lucas, A. (1996). Outlier Robust Unit Root Analysis. Thesis Publishers, Amsterdam. http://staff. feweb.vu.nl/alucas/thesis/default.htm.

Novovičova, J. (1987). Recursive computation of M-estimates for the parameters of the linear dynamical system. Problems of Control and Information Theory, 16(1), 19-59.

Pupeikis, R. (1991). Recursive robust estimation of dynamic systems parameters. Informatica, 2(4), 579-592.

Pupeikis, R. (2000). Closed-loop robust identification using the direct approach. Informatica, 11(2), 163-178.

Pupeikis, R. (2009). On a parameter adaptive self-organizing system with the minimum variance control law in the presence of large outliers in observations. Information Technology and Control, 38(4), 294-300.

Tham, M.T. (1999). Minimum Variance and Generalized Minimum Variance Control Algorithms. University of Newcastle upon Tyne: Set of notes.

http: //lorien.ncl.ac.uk/ming/digicont/mbpc/gmv.pdf .

Vörös, J. (2010). Recursive identification of systems with noninvertible output nonlinearities. Informatica, 21(1) 139-148.

Waller, M., Saxén, H. (2000). Estimating the degree of time variance in a parametric model. Automatica, 36, $619-625$. 
R. Pupeikis received PhD degree from the Kaunas Polytechnic Institute, Kaunas, Lithuania, 1979. He is a senior researcher at the Process Recognition Department of the Institute of Mathematics and Informatics and an associated professor at the Gediminas Technical University. His research interest include the digital signal processing, robust approaches of dynamic system identification as well technological process control.

\section{Apie laike besikeičiančiu parametru atžvilgiu adaptyviaja savitvarkẹ sistema, esant dideliems triukšmu impulsams stebėjimuose}

\section{Rimantas PUPEIKIS}

Straipsnyje nagrinejjama grį̌tamojo ryšio diskrečiojo laiko tiesinė dinaminė sistema, veikianti pagal mažiausiosios dispersijos valdymo (MDV) dèsni. Dinaminès sistemos bei reguliatoriaus koeficientai keičiasi laikui bẻgant ir nẻra žinomi. Jie turi būti ịvertinami pagal ịejjimo bei užtriukšminto išejjimo stebejjimus. Triukšmuose atsitiktiniais laiko momentais pasirodo reti didelès amplitudès impulsai. Siūloma sistemos parametrams ịvertinti taikyti rekurentinius patvariuosius algoritmus su pasenusios informacijos užmiršimu pagal eksponentinị dèsnị, o jos valdymo signalo einamajai reikšmei gauti - papildomo modelio išejimą, laisvą nuo triukšmų. Pateikti II eilès MDV sistemos su kintamaisiais koeficientais modeliavimo rezultatai. 